OPEN ACCESS

Edited by:

Paolo De Fabritiis,

University Tor Vergata, Italy

Reviewed by:

Luca Cupelli,

Sant'Eugenio Hospital, Italy

Maria Teresa Petrucci,

Sapienza University of Rome, Italy

*Correspondence:

Nainong $\mathrm{Li}$

nainli@aliyun.com

Yuanzhong Chen

chenyz@fimu.edu.cn

${ }^{\dagger}$ These authors have contributed equally to this work

Specialty section:

This article was submitted to Hematologic Malignancies,

a section of the journa

Frontiers in Oncology

Received: 30 November 2021 Accepted: 10 January 2022

Published: 27 January 2022

Citation:

Zhu Z, Li X, Liu Y, Chen P, Chen X, Li H, Huang J, Chen Y and Li N (2022) High Efficacy of Stem Cell Mobilization With Etoposide+ Cytarabine Plus G-CSF in Patients With Multiple Myeloma.

Front. Oncol. 12:825550. doi: 10.3389/fonc.2022.825550

\section{High Efficacy of Stem Cell Mobilization With Etoposide +Cytarabine Plus G-CSF in Patients With Multiple Myeloma}

\author{
Zhijuan Zhu ${ }^{1 \dagger}$, Xiaofan $\mathrm{Li}^{1,2 \dagger}{ }^{1}$, Yiping Liu ${ }^{1}$, Ping Chen ${ }^{1}$, Xianling Chen ${ }^{1}$, Hua $\mathrm{Li}^{1}$, \\ Jiafu Huang ${ }^{1}$, Yuanzhong Chen ${ }^{1,2^{\star}}$ and Nainong $\mathrm{Li}^{1,2^{\star}}$ \\ 1 Fujian Institute of Hematology, Fujian Provincial Key Laboratory on Hematology, Fujian Medical University Union Hospital, \\ Fuzhou, China, ${ }^{2}$ Translational Medicine Center on Hematology, Fujian Medical University, Fuzhou, China
}

Background: Efficient mobilization of CD34+ hematopoietic stem cells plays a vital role in successful autologous stem cell transplantation (ASCT) in patients with multiple myeloma (MM), especially in cases with high-risk cytogenetic recommended for tandem ASCT. However, the optimal mobilization strategy remains a matter of debate in the era of lenalidomide. The combination of etoposide with Cytarabine plus G-CSF as a novel mobilization regimen in MM has not been reported previously.

Methods: This research retrospectively studied mobilization efficacy and safety using etoposide combined with Cytarabine (etoposide 50-100 mg/m², qd d1-3; AraC $0.5 \mathrm{~g} / \mathrm{m}^{2}$, q12h d1 3) plus G-CSF (5 $\mathrm{gg} / \mathrm{kg} /$ day, from d5 until the day of apheresis) in 128 patients with MM. 70(54.7\%) patients received lenalidomide-based induction regimens treatment

Results: A median of $27.75 \times 10^{6} \mathrm{CD} 34+$ cells $/ \mathrm{kg}$ was collected in the first apheresis, and $28.23 \times 10^{6} \mathrm{CD} 34+$ cells $/ \mathrm{kg}$ were collected overall. Of the 128 patients, all achieved adequate collection ( $\geq 2 \times 10^{6} \mathrm{CD} 34+$ cells $\left./ \mathrm{kg}\right), 121(94.5 \%)$ achieved optimal collection for single ASCT ( $\geq 5 \times 10^{6} \mathrm{CD} 34+$ cells $/ \mathrm{kg}$ ), and 114(89.1\%) harvested optimal collection for tandem ASCT $\left(\geq 10 \times 10^{6} \mathrm{CD} 34+\right.$ cells $\left./ \mathrm{kg}\right)$. In particular, the target yield of optimal collection for tandem ASCT was reached in $82.8 \%(106 / 128)$ by a single apheresis procedure. 14 patients obtained deeper response post mobilization. In multivariate analysis, cycles of prior chemotherapy independently affected the optimal achievement of CD34+ cells ( $p=0.004$, OR $0.695,95 \% \mathrm{Cl} 0.544 \sim 0.888$ ). Previous lenalidomide exposure did not significantly impair CD34+ cells collection. Although 68\% episodes of antibiotic usage were observed, no severe infection or treatment-related mortality occurred.

Conclusion: Stem cell mobilization with Etoposide + Cytarabine plus G-CSF was highly efficient and safe in patients with MM, which could be considered in high-risk MM patients who were referred for tandem ASCT.

Keywords: Etoposide, Cytarabine, granulocyte colony-stimulating factor, stem cell mobilization, multiple myeloma 


\section{INTRODUCTION}

High-dose chemotherapy followed by autologous stem cell transplantation (ASCT) is an important option for transplanteligible patients with multiple myeloma $(\mathrm{MM})(1,2)$, which can significantly improve patients' outcomes. Moreover, tandem ASCT is currently recommended in patients with $\mathrm{MM}$ and high-risk disease according to the presence of cytogenetic abnormalities (3). Adequate collection of CD34+ hematopoietic stem cells (HSCs) is important for successful engraftment post-ASCT, and high collection is associated with faster hematologic recovery, reduced infection risk, and improved overall survival $(4,5)$.

At present, the commonly utilized mobilization strategies include cytokine mobilization such as granulocyte colonystimulating factor (G-CSF); chemo-mobilization using chemotherapy, followed by cytokine administration, such as the use of cyclophosphamide (Cy) prior to G-CSF; and CXCR4 inhibitor plerixafor mobilization (6). Cy plus G-CSF is currently a wildly used regimen for HSC mobilization in patients with MM. Although published literatures on these mobilization approaches have reported encouraging mobilization efficacy, approximately $5 \%-40 \%$ of patients fail to collect adequate dose of HSCs $(7,8)$ because of tumor burden, previous treatments such as lenalidomide, and age of patients $(5,6)$. Furthermore, the use of Cy during chemo-mobilization has been linked to increased morbidity such as febrile neutropenia (9), and plerixafor administration is associated with high cost, which has led to its restricted use as a pre-emptive regimen for patients at high risk for mobilization failure $(10,11)$. Thus, the optimal regimen for the cost-efficient collection of HSCs remains a challenge, particularly in patients with MM who were referred for tandem ASCT.

Etoposide or Cytarabine (AraC) plus G-CSF administrated as chemo-mobilization had been reported in patients with MM for the past years with potential outcomes (12-16). At present, etoposide $\left(375 \mathrm{mg} / \mathrm{m}^{2}\right)$ plus G-CSF was reported as an effective and safe method of mobilization in patients with MM (14). The median number of collected CD $34+$ cells was $5.58 \times 10^{6} / \mathrm{kg}$, and the adequate harvest rate was $96.9 \%$, which was higher than that of HD-Cy. However, only $71.9 \%$ of patients achieved the optimal harvest. Moreover, AraC plus G-CSF was more efficient than Cy + G-CSF as a stem cell mobilization regimen of MM (15). Compared with $\mathrm{Cy}$, intermediate-dose $\mathrm{AraC}$ as a mobilization regimen achieved a higher peak concentration of CD34+ cells in the blood and higher CD34+ yield. Thus, we administered etoposide combined with AraC (EA) plus G-CSF clinically for patients with MM who were eligible for ASCT, to improve the cost-efficacy and safety of HSC mobilization. In this study, we aimed to retrospectively analyze the efficacy and safety of our novel protocol and explore factors affecting mobilization outcomes.

\section{PATIENTS AND METHODS}

\section{Patients}

We retrospectively analyzed 128 patients with newly diagnosed MM who underwent peripheral blood stem cell (PBSC) mobilization for ASCT at Fujian Medical University Affiliated Union Hospital between March 2013 and October 2021. Mobilization for stem cell collection was conducted in patients eligible for ASCT. Patients undergoing mobilization for tandem ASCT or ASCT at the outset of salvage therapy for relapsed disease were also included. The treatment response was determined using the International Myeloma Working Group criteria (17). Cytogenetic risk was classified according to Mayo Stratification for Myeloma and Risk-Adapted Therapy 3.0 (mSMART3.0). Adverse events were graded using The Common Terminology Criteria for Adverse Events Version 4.0 (CTCAEv4). Deep response was defined as very good partial remission (VGPR) or better. The study protocol was approved by the ethics committee of Union Hospital, Fujian Medical University. Informed consent was obtained from all patients before the study.

\section{Mobilization Regimens and Leukapheresis}

All patients received EA (etoposide $50-100 \mathrm{mg} / \mathrm{m}^{2}$, qd d1-3; AraC $0.5 \mathrm{~g} / \mathrm{m}^{2}, \mathrm{q} 12 \mathrm{~h} \mathrm{~d} 1 \sim 3$ ), and G-CSF (5 $\mu \mathrm{g} / \mathrm{kg} /$ day) was administered from d5 until the day of apheresis. Etoposide dosage was adjusted according to renal function. Collection was initiated according to the value of CD34+ cells or hematopoietic progenitor cell count in the peripheral blood, and the primary yield target was $\geq 2.0 \times 10^{6} / \mathrm{kg}$ for single ASCT and $\geq 4 \times 10^{6} / \mathrm{kg}$ for tandem ASCT. During 2013 2016, the first 15 patients stayed in the hematology ward during the whole mobilization period. Since 2017, the subsequent 113 patients were hospitalized for 3 days for chemotherapy administration, and then they received G-CSF daily administered for 6 days in outpatient clinic. All patients were asked to re-hospitalize on d10 and discharged after apheresis finished and meet the discharge standard. All patients received peripherally inserted central catheter (PICC) for the administration of mobilization chemotherapy, as well as for the subsequent transplantation condition regimen.

\section{ASCT and Engraftment}

High-dose melphalan (140 mg/m2 IV) was used as a conditioning regimen for patients with MM. G-CSF $(5 \mu \mathrm{g} / \mathrm{kg} /$ day) was administrated 5 days post-ASCT and continued until neutrophil was engrafted. Neutrophil and platelet engraftment was defined according to the guideline on post-transplant essential data from the Center for International Blood and Marrow Transplantation Research (CIBMTR).

\section{Efficacy Assessment}

Optimal mobilization was defined as a mobilized CD34+ cell count of $\geq 5 \times 10^{6} / \mathrm{kg}$, and adequate mobilization was defined as a mobilized CD $34+$ cell count of $\geq 2 \times 10^{6} / \mathrm{kg}(6,18)$. Adverse events included grade 4 hematologic toxicity (according to the Common Terminology Criteria for Adverse Events version 4.0 ), and infection complication was defined as the presence of antibiotic administration because of infection. Importantly, no antibiotics were used as prophylaxis. 


\section{Statistical Analysis}

Data analysis was performed using the IBM Statistical Package for Social Sciences version 25.0. Normality of data was tested using the kolmogorov-smirnov $\mathrm{Z}$ test. Categorical variables were compared by the $\chi 2$ test or exact test. The chi-square test or the Mann-Whitney $U$ test was used to compare differences of variables between groups. To identify predictive factors for optimal harvest, univariate, and multivariate analyses by logistic regression were performed. A two-sided value of $p<0.05$ was considered statistically significant for all analyses.

\section{RESULTS}

\section{Patient Characteristics}

A total of 128 patients were enrolled in this study. The median age was 56 years (range: 26-67 years), and 23.4\% (30/128) patients were aged over 60 years. 13.3\% (17/128) of patients weighed over $75 \mathrm{~kg}$. Before mobilization, 99 (77.3\%) patients achieved deep response, $42(32.8 \%)$ patients received $\geq 2$ lines of preceding therapy and $70(54.7 \%)$ received lenalidomide-based induction regimens treatment. $64.3 \%$ patients who received $\geq 2$ lines of preceding therapy achieved deep response (VGPR or better), lower than that of patients received first line of treatment (83.7\%, $p=0.014)$. Moreover, the median cycle of prior chemotherapies was 4 . Totally, 9 patients were diagnosed with chronic kidney disease ( 1 in CKD2 stage, 4 in CKD3 stage and 4 in CKD4 stage) prior mobilization chemotherapy administration. Patients on dialysis were excluded for using EA regimen and mobilization. Patient characteristics are summarized in Table $\mathbf{1}$.

\section{Efficacy of Mobilization}

CD34+ cells were detected in all PBSCs collected from the patients using flow cytometry. The median peak number of circulating CD34+ cells was 80/ul, and the median number of overall collected CD $34+$ cells was $28.23 \times 10^{6} / \mathrm{kg}$. There was no difference in overall collected CD34+ cells between patients who were exposed to previous lenalidomide and those were not $\left(25.59 \times 10^{6} / \mathrm{kg}\right.$ and $\left.33.27 \times 10^{6} / \mathrm{kg}, p=0.34\right)$. Of the patients, all achieved adequate collection, and $94.5 \%$ (121/128) achieved optimal collection. Moreover, 89.1\% (114/128) of patients obtained at least $10 \times 10^{6} / \mathrm{kg} \mathrm{CD} 34+$ cells, thereby achieving optimal mobilization target for tandem ASCT. In particular, 124(96.9\%) patients with MM yielded adequate harvest, and 116 (90.6\%) patients achieved optimal mobilization through the first apheresis session. A single apheresis was sufficient to collect at least $10 \times 10^{6} / \mathrm{kg} \mathrm{CD} 34+$ cells in $82.8 \%(106 / 128)$ of patients with MM. Furthermore, the overall median interval of mobilization to collection was 14 days. The median length of hospitalization was 15 days (range: 13 18 days) for the first 15 patients during 2013 2016, and 8 days (range: 5 23 days) for the subsequent 112 patients during 2017 2021. The results are summarized in Table 2.

Age, ISS stage, prior lenalidomide exposure, deep response to induction, the number of peripheral blood CD34+ cells at the
TABLE 1 | Patient characteristics.

\begin{tabular}{|c|c|}
\hline Variables & $\begin{array}{c}\text { Total } \\
(n=128)\end{array}$ \\
\hline Age, years, median(range) & $56(26 \sim 67)$ \\
\hline Sex, male, $n(\%)$ & $79(61.7 \%)$ \\
\hline Weight $>75 \mathrm{~kg}, n(\%)$ & $17(13.3 \%)$ \\
\hline \multicolumn{2}{|l|}{ ISS stage, $n(\%)$} \\
\hline 1 & $36(28.3 \%)$ \\
\hline 2 & $46(36.2 \%)$ \\
\hline 3 & $45(35.4 \%)$ \\
\hline \multicolumn{2}{|l|}{ Diagnosis, $n(\%)$} \\
\hline $\lg G$ & $69(53.9 \%)$ \\
\hline $\lg A$ & $28(21.9 \%)$ \\
\hline Light chains & $25(19.5 \%)$ \\
\hline $\lg \mathrm{D}$ & $3(2.3 \%)$ \\
\hline $\lg M$ & $2(1.6 \%)$ \\
\hline biclonal gammopathy ${ }^{\mathrm{a}}$ & $1(0.8 \%)$ \\
\hline \multicolumn{2}{|l|}{ Cytogenetic risk ${ }^{\mathrm{b}}, n(\%)$} \\
\hline high risk & $58(45.3 \%)$ \\
\hline standard risk & $49(38.3 \%)$ \\
\hline NA & $21(16.4 \%)$ \\
\hline Month from diagnosis to mobilization, median (range) & $4(2 \sim 74)$ \\
\hline Lenalidomide-included therapy, $n(\%)$ & $70(54.7 \%)$ \\
\hline \multicolumn{2}{|l|}{ Lines of preceding therapy, $n(\%)$} \\
\hline 1 & $86(67.2 \%)$ \\
\hline 2 & $33(25.8 \%)$ \\
\hline 3 & $8(6.3 \%)$ \\
\hline 4 & $1(0.8 \%)$ \\
\hline Cycles of preceding therapy, median(range) & $4(2 \sim 16)$ \\
\hline \multicolumn{2}{|l|}{ Response to induction treatment, $n(\%)$} \\
\hline VGPR or better & $99(77.3 \%)$ \\
\hline PR & $22(17.2 \%)$ \\
\hline MR & $2(1.6 \%)$ \\
\hline SD & $3(2.3 \%)$ \\
\hline PD & $2(1.6 \%)$ \\
\hline
\end{tabular}

MM, multiple myeloma; ISS, international staging system; VGPR, very good partial remission. ${ }^{a}, \lg G$ and IgA biclonal gammopathy. ${ }^{b}$, risk classification according to mSMART3.0; PR, partial remission; MR, minimal remission; SD, stable disease; $P D$, progressive disease.

TABLE 2 | Mobilization efficacy.

\begin{tabular}{|c|c|c|}
\hline Variables & $\begin{array}{c}\text { Total } \\
(n=128)\end{array}$ & $\begin{array}{l}\text { Lenalidomide } \\
\text { explosure }(n=70)\end{array}$ \\
\hline $\begin{array}{l}\text { Total CD34+ cells collected, } \times 10^{6} / \mathrm{kg} \text {, } \\
\text { median (range) }\end{array}$ & $28.23(2.51 \sim 464.3)$ & 25.59(2.57 118.77) \\
\hline \multicolumn{3}{|l|}{ Total Collection target, $n$ (\%) } \\
\hline$\geq 2 \times 10^{6} \mathrm{CD} 34+$ cells $/ \mathrm{kg}$ & $128(100 \%)$ & $70(100 \%)$ \\
\hline$\geq 5 \times 10^{6} \mathrm{CD} 34+$ cells $/ \mathrm{kg}$ & $121(94.5 \%)$ & $66(94.3 \%)$ \\
\hline$\geq 10 \times 10^{6} \mathrm{CD} 34+$ cells $/ \mathrm{kg}$ & $114(89.1 \%)$ & 65(92.9\%) \\
\hline \multicolumn{3}{|l|}{ Day 1 pheresis day target, $n(\%)$} \\
\hline$\geq 2 \times 10^{6} \mathrm{CD} 34+$ cells $/ \mathrm{kg}$ & 124(96.9\%) & $67(95.7 \%)$ \\
\hline$\geq 5 \times 10^{6}$ CD34+ cells $/ \mathrm{kg}$ & $116(90.6 \%)$ & $62(88.6 \%)$ \\
\hline$\geq 10 \times 10^{6} \mathrm{CD} 34+$ cells $/ \mathrm{kg}$ & $106(82.8 \%)$ & $60(85.7 \%)$ \\
\hline \multicolumn{3}{|l|}{ Day 1 and 2 pheresis target, $n(\%)$} \\
\hline$\geq 2 \times 10^{6} \mathrm{CD} 34+$ cells $/ \mathrm{kg}$ & $127(99.2 \%)$ & $70(100 \%)$ \\
\hline$\geq 5 \times 10^{6}$ CD34+ cells $/ \mathrm{kg}$ & $121(94.5 \%)$ & $66(94.3 \%)$ \\
\hline$\geq 10 \times 10^{6} \mathrm{CD} 34+$ cells $/ \mathrm{kg}$ & $114(89.1 \%)$ & $65(92.9 \%)$ \\
\hline $\begin{array}{l}\text { Days of leukapheresis initiation, } \\
\text { median(range) }\end{array}$ & $14(8 \sim 21)$ & 14(8 21) \\
\hline \multicolumn{3}{|l|}{ Days of pheresis, $n(\%)$} \\
\hline 1 day & 107(83.6\%) & $58(82.9 \%)$ \\
\hline 2 days & $20(15.6 \%)$ & $12(17.1 \%$ \\
\hline 3 days & $1(0.8 \%)$ & $0(0 \%)$ \\
\hline
\end{tabular}

MM, multiple myeloma. 
first day of apheresis, cycles of prior therapy were considered for multivariate analysis to explore the factors associated with failure to achieve optimal mobilization. The result showed that cycles of prior chemotherapy independently affected the optimal achievement of CD34+ cells in patients with MM ( $p=0.004$, OR 0.695, 95\% CI 0.544 0.888). Previous lenalidomide exposure did not significantly decrease the absolute number of CD34+cells collected.

\section{Adverse Events}

The most common complication was hematologic toxicity. The mean duration of grade 4 neutropenia was longer compared to that of grade 4 thrombocytopenia (3.36 days and 3.00 days, respectively, $p<0.01)$. However, no bleeding episode was observed. A relatively shorter duration of thrombocytopenia indicated fewer amounts of platelet transfusion (median1.6, range: 0 6) before apheresis. During mobilization, 87 (68\%) patients received antibiotic administration, no mortality occurred during mobilization. Generally, 85 patients suffered grade $2 \sim 3$ infections, while grade 4 infections were found in only 2 patients (septic shock complication). The infections sites include respiratory tract, oral cavity mucosa, septicemia, soft tissue infection, digestive tract and febrile neutropenia unknown origin. The common infections were respiratory tract and fever unknown origin. And the median duration of antibiotic administration was 4 days (range 1 13 days). Toxicity information are summarized in Table 3.

\section{Hematologic Recovery After ASCT}

A total of 125 patients underwent ASCT as planned, except for 3 patients who are still waiting in line for receiving ASCT. In particular, $70 \mathrm{MM}$ patients underwent tandem ASCT as planned. All patients achieved hematologic recovery post-HSC infusion, and both the median interval time of neutrophil and platelet engraftment was 11 days. Importantly, we found 14 patients achieved deeper responses after mobilization. Detailed data concerning hematologic reconstitution are summarized in Table 4.

\section{DISCUSSION}

The recommended adequate mobilization is at least $2 \times 10^{6}$ $\mathrm{CD} 34+$ cells $/ \mathrm{kg}$, as an infusion less than this value can impair

TABLE 3 | Common toxicities.

\begin{tabular}{lc}
\hline Variables & $\begin{array}{c}\text { Total } \\
(\boldsymbol{n}=\mathbf{1 2 8})\end{array}$ \\
\hline Days of Grade 4 Neutropenia, median (range) & $3(0 \sim 6)$ \\
Days of Grade 4 Thrombocytopenia, median (range) & $3(0 \sim 6)$ \\
Platelet transfusions, median (range) & $1.6(0 \sim 6)$ \\
Erythrocyte transfusions, median (range) & $0(0 \sim 4)$ \\
Infection, $n$ (\%) & \\
grade 2 & $4(3.1 \%)$ \\
grade 3 & $81(63.3 \%)$ \\
grade 4 & $2(1.6 \%)$ \\
\hline
\end{tabular}

MM, multiple myeloma.
TABLE 4 | Hematologic recovery after ASCT.

\begin{tabular}{lc}
\hline Variables & $\begin{array}{c}\text { Total } \\
(\boldsymbol{n}=\mathbf{1 2 5})\end{array}$ \\
\hline Months from diagnosis to transplantation, & $6(4 \sim 75)$ \\
median(range) & \\
Day of reach, median (range) & \\
$\quad$ Neutrophils $\geq 0.5 \times 10^{9} /$ ul & $11(0 \sim 38)$ \\
PLT $\geq 20 \times 10^{9} /$ ul & $11(0 \sim 48)$ \\
Platelet transfusions, median (range) & $1.8(0 \sim 20.6)$ \\
Erythrocyte transfusions, median (range) & $0(0 \sim 14.5)$ \\
\hline
\end{tabular}

engraftment (6). Moreover, this target yield must be higher in patients with MM because of a possible second transplantation, such as tandem ASCTs in high-risk diseases (3). Successful mobilization of PBSCs predicts favorable outcomes in patients with $\mathrm{MM}(4,6)$, whereas poor PBSCs mobilization is significantly associated with shortened progression free survival and overall survival compared with good mobilizers $(5,19)$. Hence, the recommended optimal CD34+ cell dose is at least $5 \times 10^{6} / \mathrm{kg}(8,20)$. Using modern agents such as lenalidomide's induction as first-line treatment in transplanteligible patients, impaired mobilization after its administration has been raised $(7,21-23)$. However, stem cell collection through repeated apheresis may physically and economically burden patients and increase complications. Thus, the goal of mobilization is to cost-effectively collect sufficient HSCs using the least number of apheresis procedures with minimal mobilization-related complications.

Various attempts have been proposed to increase the efficacy of mobilization regimens. One option is the administration of an additional chemotherapy regimen plus G-CSF. Among chemomobilization protocols, intermediate-dose CY has been widely used $(9,24)$. Recently, single-dose etoposide or intermediatedose AraC as mobilization regimens with G-CSF has been reported to reach encouraging results compared with $\mathrm{CY}$ in patients with $\mathrm{MM}$ and lymphoma $(13-15,25)$. Our findings showed that the use of etoposide combined with AraC plus GCSF regimen could increase the adequate and optimal collection rates in patients with $\mathrm{MM}(100 \%$ vs. $94.5 \%)$ by 1.2 and 1.1 apheresis procedures (mean), respectively. Importantly, $89.1 \%$ of patients with $\mathrm{MM}$ reached optimal mobilization for tandem ASCT $(\geq 10 \times 106$ CD34+ cells $/ \mathrm{kg})$ through minimal apheresis. This advantage contributed to the reduction of stem cell mobilization costs and apheresis-associated complications.

Risk factors for mobilization failure, including aging, prior treatment with lenalidomide, heavily preceding treatment, and diagnosis have been established $(6,19,26)$. In our study, we considered cycles of prior chemotherapy as an independent risk factor influencing the achievement of optimal harvest in patients with $\mathrm{MM}$, which implied that the novel regimen might overcome the negative impact of lenalidomide on mobilization. This result was consistent with recent reports (27). Commonly used mobilizations based on chemotherapy have been observed with $0 \%-73 \%$ of grade 4 neutropenia and $0 \%-50 \%$ of grade 4 thrombocytopenia $(12,13,15)$. Although the duration of grade 4 hematological toxicity or antibiotic administration was short, 
and no mobilization-related mortality was observed, the occurrences were more common in our protocol. As intermediate-dose $\operatorname{AraC}\left(1.6 \mathrm{~g} / \mathrm{m}^{2}\right)$ was associated with a high adequate mobilization rate with slight hematologic complication $(12,13,15)$, decreasing the AraC's dosage in our regimen might be an option to reduce complications without affecting mobilization efficacy.

Whether chemotherapy contributes to the outcome of ASCT and the depth of response has been discussed over years because it is originally intended to reduce tumor burden by additional exposure to cytotoxic agents. However, a previous retrospective analysis of 968 patients with MM from the CIBMTR database reported similar prognosis of 3-year progression-free survival ( $43 \%$ vs. $40 \%, p=0.33$ ) and overall survival ( $82 \%$ vs. $80 \%, p=0.43$ ) between G-mobilization and chemo-mobilization (28). Another work demonstrated that chemotherapy-based stem cell mobilization does not contribute to disease control in the era of novel induction regimens $(29,30)$. In our study, 117 patients with MM were assessed disease status before mobilization and prior autologous transplantation, respectively. We observed that 14 patients obtained deeper response depth post mobilization, which indicated that our new protocol might contribute to disease control. However, it needs further prospective clinical investigation to confirm the current result. High-dose cytotoxic agents as part of mobilization might damage human mesenchymal stem cells, resulting in delayed engraftment after ASCT. In our study, the median days to neutrophil and platelet engraftment post-transplantation were comparable with those recently published $(12,14,15,28)$.

\section{CONCLUSIONS}

Collectively, we have demonstrated that etoposide combined with AraC plus G-CSF is an efficient and safe regimen for CD34+ PBSC mobilization in patients with MM. This novel regimen might be an option particularly for high-risk MM patients who are referred for tandem ASCTs and cases where use plerixafor in MM is difficult. Nevertheless, this research is not a prospective randomized study that directly compares the costefficacy and safety of etoposide + AraC plus G-CSF with common mobilization protocols. Therefore, our conclusion

\section{REFERENCES}

1. Moreau P, San Miguel J, Sonneveld P, Mateos M, Zamagni E, Avet-Loiseau H, et al. Multiple Myeloma: ESMO Clinical Practice Guidelines for Diagnosis, Treatment and Follow-Up. Ann Oncol (2017) 28:iv52-61. doi: 10.1093/ annonc/mdx096

2. Kumar S, Callander N, Adekola K, Anderson L, Baljevic M, Campagnaro E, et al. Multiple Myeloma, Version 3.2021, NCCN Clinical Practice Guidelines in Oncology. J Natl Compr Cancer Netw: JNCCN (2020) 18(12):1685-717. doi: 10.6004/jnccn.2020.0057

3. Gagelmann N, Eikema D, Koster L, Caillot D, Pioltelli P, Lleonart J, et al. Tandem Autologous Stem Cell Transplantation Improves Outcomes in Newly Diagnosed Multiple Myeloma With Extramedullary Disease and High-Risk Cytogenetics: A Study From the Chronic Malignancies Working must be confirmed prospectively with a larger randomized trial in the future.

\section{DATA AVAILABILITY STATEMENT}

The original contributions presented in the study are included in the article/supplementary material. Further inquiries can be directed to the corresponding authors.

\section{ETHICS STATEMENT}

The studies involving human participants were reviewed and approved by the ethics committee of Union Hospital, Fujian Medical University. The patients/participants provided their written informed consent to participate in this study.

\section{AUTHOR CONTRIBUTIONS}

ZZ, XL: data collection, data analysis and interpretation, manuscript writing, manuscript revision, final approval of manuscript. YL: data collection, data analysis and interpretation, final approval of manuscript. PC, XC, HL, JH: data analysis and interpretation, final approval of manuscript. NL, YC: study design, data analysis and interpretation, manuscript revision, final approval of manuscript. All the authors read and approved the final manuscript.

\section{FUNDING}

This work was supported by Department of Science and Technology of Fujian Province Project (2017I0004 and 2017Y9057); Fujian provincial health technology project (2021ZD01005); Top Notch Innovative Talents Project and Fujian Project(2016Y9025 and 2016J06018); National Key Clinical Specialty Discipline Construction Program(2021-76); This work was also sponsored by Fujian Provincial Clinical Research Center for Hematological Malignancies (2020Y2006); and Fujian Provincial Key Clinical Specialty Discipline Construction Program, P. R.C. Blood Marrow Transplant: J Am Soc Blood Marrow Transplant (2019) 25 (11):2134-42. doi: 10.1016/j.bbmt.2019.07.004

4. Brioli A, Perrone G, Patriarca F, Pezzi A, Nobile F, Ballerini F, et al. Successful Mobilization of PBSCs Predicts Favorable Outcomes in Multiple Myeloma Patients Treated With Novel Agents and Autologous Transplantation. Bone Marrow Transplant (2015) 50(5):673-8. doi: 10.1038/bmt.2014.322

5. Moreb JS, Byrne M, Shugarman I, Zou F, Xiong S, May WS, et al. Poor Peripheral Blood Stem Cell Mobilization Affects Long-Term Outcomes in Multiple Myeloma Patients Undergoing Autologous Stem Cell Transplantation. J Clin Apher (2018) 33(1):29-37. doi: 10.1002/jca.21556

6. Giralt S, Costa L, Schriber J, Dipersio J, Maziarz R, McCarty J, et al. Optimizing Autologous Stem Cell Mobilization Strategies to Improve Patient Outcomes: Consensus Guidelines and Recommendations. Biol 
Blood Marrow Transplant (2014) 20(3):295-308. doi: 10.1016/ j.bbmt.2013.10.013

7. Arora S, Majhail NS, Liu H. Hematopoietic Progenitor Cell Mobilization for Autologous Stem Cell Transplantation in Multiple Myeloma in Contemporary Era. Clin Lymphoma Myeloma Leuk (2019) 19(4):200-5. doi: 10.1016/j.clml.2018.12.010

8. Hopman RK, DiPersio JF. Advances in Stem Cell Mobilization. Blood Rev (2014) 28(1):31-40. doi: 10.1016/j.blre.2014.01.001

9. Gertz M, Kumar S, Lacy M, Dispenzieri A, Hayman S, Buadi F, et al. Comparison of High-Dose CY and Growth Factor With Growth Factor Alone for Mobilization of Stem Cells for Transplantation in Patients With Multiple Myeloma. Bone Marrow Transplant (2009) 43(8):619-25. doi: 10.1038/bmt.2008.369

10. Afifi S, Adel N, Devlin S, Duck E, Vanak J, Landau H, et al. Upfront Plerixafor Plus G-CSF Versus Cyclophosphamide Plus G-CSF for Stem Cell Mobilization in Multiple Myeloma: Efficacy and Cost Analysis Study. Bone Marrow Transplant (2016) 51(4):546-52. doi: 10.1038/bmt.2015.322

11. Mohty M, Duarte RF, Croockewit S, Hubel K, Kvalheim G, Russell N. The Role of Plerixafor in Optimizing Peripheral Blood Stem Cell Mobilization for Autologous Stem Cell Transplantation. Leukemia (2011) 25(1):1-6. doi: 10.1038/leu.2010.224

12. Callera AF, Rosa ES, Callera F. Intermediate-Dose Cytarabine Plus G-CSF as Mobilization Regimen for Newly Diagnosed Multiple Myeloma and Heavily Pre-Treated Patients With Hematological and non-Hematological Malignancies. Transfus Apher Sci (2019) 58(3):318-22. doi: 10.1016/ j.transci.2019.03.018

13. Czerw T, Sadus-Wojciechowska M, Michalak K, Najda J, Mendrek W, Sobczyk-Kruszelnicka $\mathrm{M}$, et al. Increased Efficacy of Stem Cell Chemomobilization With Intermediate-Dose Cytarabine Plus Granulocyte Colony-Stimulating Factor (G-CSF) Compared With G-CSF Alone in Patients With Multiple Myeloma: Results of a Randomized Trial. Biol Blood Marrow Transplant (2019) 25(2):248-55. doi: 10.1016/j.bbmt.2018.09.023

14. Park Y, Kim DS, Jeon MJ, Lee BH, Yu ES, Kang KW, et al. Single-Dose Etoposide is an Effective and Safe Protocol for Stem Cell Mobilization in Patients With Multiple Myeloma. J Clin Apher (2019) 34(5):579-88. doi: $10.1002 /$ jca. 21734

15. Jelinek T, Adamusova L, Popkova T, Tvrda I, Smejkalova J, Simicek M, et al. Cytarabine + G-CSF is More Effective Than Cyclophosphamide + G-CSF as a Stem Cell Mobilization Regimen in Multiple Myeloma. Bone Marrow Transplant (2019) 54(7):1107-14. doi: 10.1038/s41409-018-0396-x

16. Guner SI, Yanmaz MT, Selvi A, Usul C. The High Effect of Chemomobilization With High-Dose Etopside + Granulocyte-Colony Stimulating Factor in Autologous Hematopoietic Peripheral Blood Stem Cell Transplantation: A Single Center Experience. Hematol Rep (2016) 8 (1):6319. doi: 10.4081/hr.2016.6319

17. Durie B, Harousseau J, Miguel J, Bladé J, Barlogie B, Anderson K, et al. International Uniform Response Criteria for Multiple Myeloma. Leukemia (2006) 20(9):1467-73. doi: 10.1038/sj.leu.2404284

18. Mohty M, Hübel K, Kröger N, Aljurf M, Apperley J, Basak G, et al. Autologous Haematopoietic Stem Cell Mobilisation in Multiple Myeloma and Lymphoma Patients: A Position Statement From the European Group for Blood and Marrow Transplantation. Bone Marrow Transplant (2014) 49(7):865-72. doi: 10.1038/bmt.2014.39

19. Wutcher P, Ran D, Bruckner T, Schmitt T, Witzens-Harig M, Neben K, et al. Poor Mobilization of Hematopoietic Stem Cells-Definitions, Incidence, Risk Factors, and Impact on Outcome of Autologous Transplantation. Biol Blood Marrow Transplant: J Am Soc Blood Marrow Transplant (2010) 16(4):490-9. doi: 10.1016/j.bbmt.2009.11.012

20. Weaver CH, Hazelton B, Birch R, Palmer P, Allen C, Schwartzberg L, et al. An Analysis of Engraftment Kinetics as a Function of the CD34 Content of Peripheral Blood Progenitor Cell Collections in 692 Patients After the Administration of Myeloablative Chemotherapy. Blood (1995) 86(10):39619. doi: 10.1182/blood.V86.10.3961.bloodjournal86103961
21. Popat U, Saliba R, Thandi R, Hosing C, Qazilbash M, Anderlini P, et al. Impairment of Filgrastim-Induced Stem Cell Mobilization After Prior Lenalidomide in Patients With Multiple Myeloma. Biol Blood Marrow Transplant: J Am Soc Blood Marrow Transplant (2009) 15(6):718-23. doi: 10.1016/j.bbmt.2009.02.011

22. Cavallo F, Bringhen S, Milone G, Ben-Yehuda D, Nagler A, Calabrese E, et al. Stem Cell Mobilization in Patients With Newly Diagnosed Multiple Myeloma After Lenalidomide Induction Therapy. Leukemia (2011) 25(10):1627-31. doi: 10.1038/leu.2011.131

23. Paripati H, Stewart A, Cabou S, Dueck A, Zepeda V, Pirooz N, et al. Compromised Stem Cell Mobilization Following Induction Therapy With Lenalidomide in Myeloma. Leukemia (2008) 22(6):1282-4. doi: 10.1038/ sj.leu. 2405100

24. Hiwase D, Bollard G, Hiwase S, Bailey M, Muirhead J, Schwarer A. Intermediate-Dose CY and G-CSF More Efficiently Mobilize Adequate Numbers of PBSC for Tandem Autologous PBSC Transplantation Compared With Low-Dose CY in Patients With Multiple Myeloma. Cytotherapy (2007) 9(6):539-47. doi: 10.1080/14653240701452800

25. Wood WA, Whitley J, Goyal R, Brown PM, Sharf A, Irons R, et al. Effectiveness of Etoposide Chemomobilization in Lymphoma Patients Undergoing Auto-SCT. Bone Marrow Transplant (2013) 48(6):771-6. doi: $10.1038 / \mathrm{bmt} .2012 .216$

26. To L, Levesque J, Herbert K. How I Treat Patients Who Mobilize Hematopoietic Stem Cells Poorly. Blood (2011) 118(17):4530-40. doi: 10.1182/blood-2011-06-318220

27. Cowan AJ, Stevenson PA, Green DJ, Tuazon S, Libby EN, Kwok M, et al. Prolonged Lenalidomide Therapy Does Not Impact Autologous Peripheral Blood Stem Cell Mobilization and Collection in Multiple Myeloma Patients: A Single-Center Retrospective Analysis. Transplant Cell Ther (2021) 27 (8):661.e1-e6. doi: 10.1016/j.jtct.2021.04.010

28. Uy GL, Costa LJ, Hari PN, Zhang MJ, Huang JX, Anderson KC, et al. Contribution of Chemotherapy Mobilization to Disease Control in Multiple Myeloma Treated With Autologous Hematopoietic Cell Transplantation. Bone Marrow Transplant (2015) 50(12):1513-8. doi: 10.1038/bmt.2015.190

29. Dingli D, Nowakowski G, Dispenzieri A, Lacy M, Hayman S, Litzow M, et al. Cyclophosphamide Mobilization Does Not Improve Outcome in Patients Receiving Stem Cell Transplantation for Multiple Myeloma. Clin Lymphoma Myeloma (2006) 6(5):384-8. doi: 10.3816/CLM.2006.n.014

30. Oyekunle A, Shumilov E, Kostrewa P, Burchert A, Trümper L, Wuchter P, et al. Chemotherapy-Based Stem Cell Mobilization Does Not Result in Significant Paraprotein Reduction in Myeloma Patients in the Era of Novel Induction Regimens. Biol Blood Marrow Transplant: J Am Soc Blood Marrow Transplant (2018) 24(2):276-81. doi: 10.1016/j.bbmt.2017.10.008

Conflict of Interest: The authors declare that the research was conducted in the absence of any commercial or financial relationships that could be construed as a potential conflict of interest.

Publisher's Note: All claims expressed in this article are solely those of the authors and do not necessarily represent those of their affiliated organizations, or those of the publisher, the editors and the reviewers. Any product that may be evaluated in this article, or claim that may be made by its manufacturer, is not guaranteed or endorsed by the publisher.

Copyright $\odot 2022 \mathrm{Zhu}, \mathrm{Li}$, Liu, Chen, Chen, Li, Huang, Chen and Li. This is an openaccess article distributed under the terms of the Creative Commons Attribution License (CC BY). The use, distribution or reproduction in other forums is permitted, provided the original author(s) and the copyright owner(s) are credited and that the original publication in this journal is cited, in accordance with accepted academic practice. No use, distribution or reproduction is permitted which does not comply with these terms. 